\title{
Diferencia que hace diferencia. Migración y organización familiar
}

\author{
Margarita Estrada Iguíniz
}

El artículo parte del planteamiento de que la emigración es una diferencia que hace diferencia, pues introduce información, experiencias, recursos económicos y culturales en las familias. Así, la organización de las familias que cuentan con emigrantes se modifica de acuerdo con la posición del integrante que emigra: padre, hijo, cónyuge. En la interrelación entre la emigración y la posición del emigrante surgen aspectos positivos para las condiciones de vida y relaciones entre los integrantes de cada familia $y$, al mismo tiempo, hay elementos que introducen tensiones $y$ conflictos.

PALABRAS CLAVE: migración, familia, solidaridad, conflicto, Guanajuato

The Difference that Makes a Difference. Immigration and Family Structure

This paper puts forward the idea that immigration constitutes a difference that makes a difference, since it provides families with information, experiences, as well as economic and cultural resources. In this way, the structure of families that include an immigrant is modified in accordance with the position of the migrant: father, son or spouse. The interrelation between immigration and the position of the migrant brings about positive aspects regarding the living standards and relationships among family members and, at the same time, some elements that generate tensions and conflicts.

KEY WORDS: immigration, family, solidarity, conflict, Guanajuato

MARGARITA ESTRADA IGUínIZ: Centro de Investigaciones y Estudios Superiores en Antropología Social-Distrito Federal, México. mei@ciesas.edu.mx 
E ste artículo explora las dinámicas que tienen lugar y las formas de organización que se desarrollan entre las familias que tienen emigrantes internacionales. El análisis retoma algunos de los planteamientos de la teoría de la complejidad ${ }^{1}$. Sólo algunos, porque una de las premisas de esta teoría supone la imposibilidad de analizar la totalidad de los aspectos que conforman un sistema, entendido como "un complejo de elementos interactuantes" (Von Bertalanffy, 1995: 56). Este supuesto se aplica, claro está, a la propia utilización de esta teoría (Morin, 2005: 137). Es imposible retomarla en su totalidad y, en la medida en que se incorporan algunos de sus planteamientos, la mirada se vuelve más compleja y nuevos aspectos tienen que ser considerados. De esta manera es imposible agotar el estudio de un sistema.

Así pues, las premisas que he utilizado para construir y analizar algunos aspectos de las dinámicas que se establecen entre la organización de personas emparentadas entre sí y los movimientos migratorios son las siguientes: en primer lugar, el pensamiento complejo busca entender los sistemas con base en la articulación de las cesos que se van encadenando en redes seriales. En estas redes las relaciones que se establecen entre las partes tienen como resultado emergentes que son de naturaleza distinta a las partes que los generaron. En estas interacciones hay retroacciones sobre las partes que inciden en las formas de organización entre ellas.

Una segunda premisa es el reconocimiento de que en la organización de cualquier sistema sus distintos aspectos pueden tener un carácter tanto positivo como negativo, de manera que lo extraño, lo discordante, también forma parte de éste y, por lo tanto, debe ser integrado en el análisis (Morin, 2001:35). Con esto lo que pretendo es mostrar cómo lo negativo y lo positivo interactúan entre sí, y en estas interacciones crean relaciones que son las que configuran las formas específicas de organización del fenómeno que me ocupa.

\footnotetext{
${ }^{1}$ La epistemología que rige este trabajo ha sido discutida, reflexionada y apropiada durante mi participación en el seminario "Percepción, pensamiento y lenguaje", que coordina el doctor José Luis Martínez Sánchez. A él y a las integrantes del grupo, mi agradecimiento.
}

Otro aspecto de la teoría de la complejidad que retomaré en este trabajo es el reconocimiento de la imposibilidad de llegar a una verdad única y definitiva, lo que nos lleva al fin de las certidumbres, como diría Prigogini (1997). Esta imposibilidad está relacionada, entre otras cosas, con las características de la observación y del observador. Es decir, con la posición del observador. Su posicionamiento se define a partir de su historia, sus experiencias, los conocimientos que ha acumulado, el contexto en que trabaja, que son los que lo llevan a formularse ciertas preguntas y a dirigir su atención a determinados aspectos del fenómeno, mientras les resta importancia o ignora otros (Devereux, 1996). En este sentido, quiero aclarar que este artículo es una mirada, de las muchas posibles, a propósito de la relación que se establece entre la migración y las familias.

Como parte de mi posicionamiento personal en este trabajo consideraré a la migración como una diferencia que hace diferencia. Con esto, Bateson se refería al hecho de que hay información que genera cambios y, por lo tanto, diferencias respecto a, por un lado, la situación previa que encaraban los protagonistas; y por otro, respecto a quienes carecen de dicha información (Bateson, 1991: 345). Así, en el caso que me ocupa la migración introduce nuevos conocimientos, amplía los recursos del grupo, implica nuevas experiencias. Desde esta perspectiva la migración es la diferencia que hace diferencia y constituye el eje que organiza este trabajo.

\section{MIGRACIÓN}

La migración es un fenómeno multidimensional que implica desplazamientos, separaciones y encuentros, pérdidas y ganancias. Es una acción que se realiza a fin de obtener trabajos que permitan mejorar las condiciones de vida y realizar proyectos que han sido pospuestos. En el caso de la migración por motivos políticos, se emprende para conservar la libertad y, en ocasiones, incluso la vida.

La migración supone el abandono de lo conocido: lugares, gente, formas de vida, y el encuentro con nuevas oportunidades, retos, experiencias y relaciones. Estas características son extensivas a cualquier tipo de migración. 


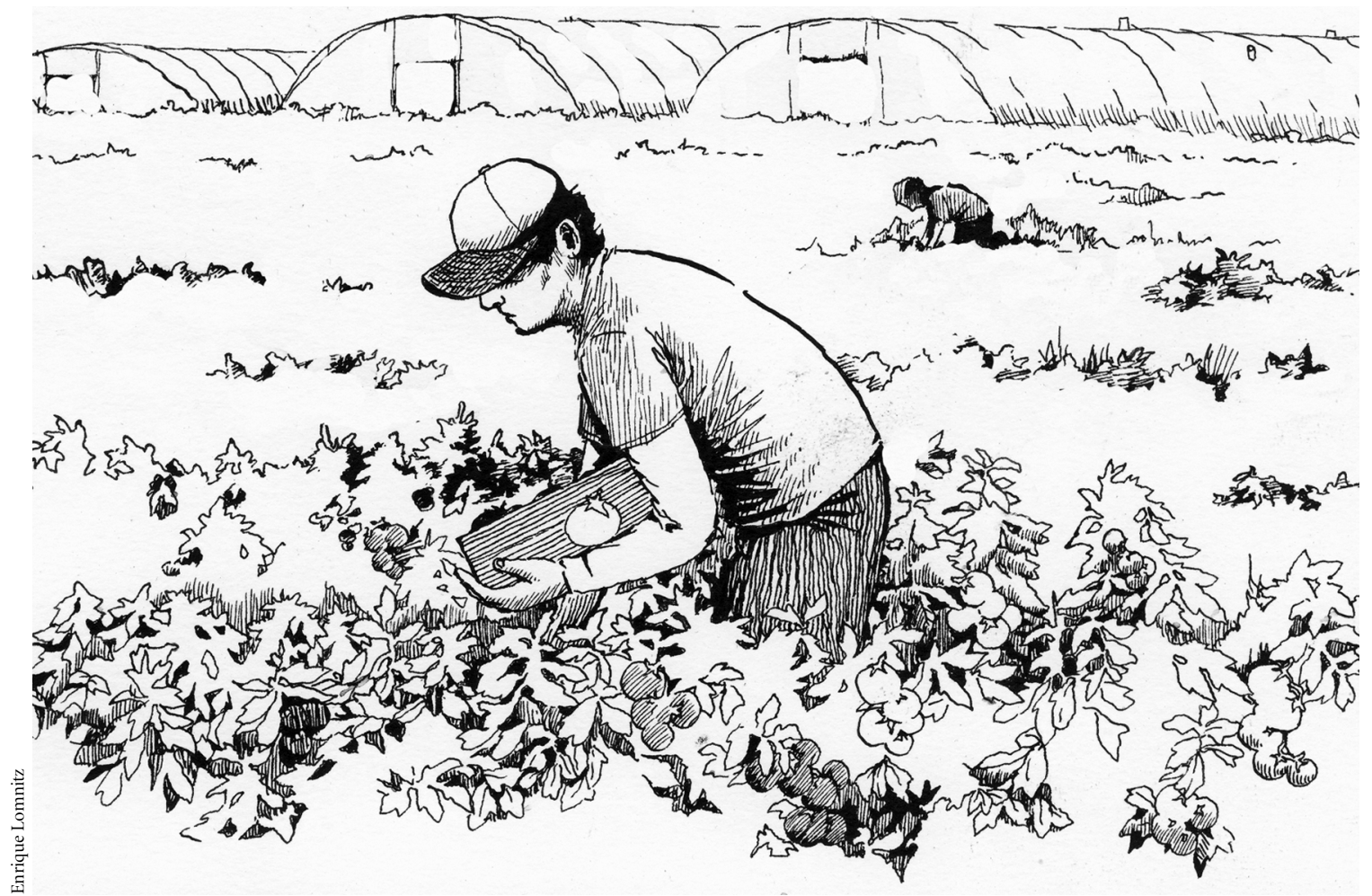

Sin embargo, en el caso de la migración internacional estos rasgos se agudizan y suelen ser diferencias que modifican las circunstancias en el lugar de origen y en el de destino.

La migración es un fenómeno de organización colectiva y, por este motivo, involucra no sólo a las familias de los que emigran, sino al conjunto de los habitantes de la localidad de donde salen. En esas localidades se generan diferencias entre los que se quedan y los que se van. En lo que respecta a las familias las diferencias se manifiestan entre las que cuentan con emigrantes y las que no. $\mathrm{Al}$ interior de éstas hay distinciones entre los que se quedan y los que se van, entre progenitores e hijos e hijas, entre cónyuges, entre hermanos y hermanas. Estas distinciones tienen como resultado formas de relación entre los integrantes que son de una naturaleza diferente a las relaciones que se establecen en las familias en las que todos los miembros viven bajo el mismo techo o en la misma localidad.
En el lugar de destino, la migración supone la inserción de la persona en una red preexistente. El emigrante conocía su existencia, sin embargo, desconocía la forma de operación en el lugar de destino. Al insertarse en la red de emigrantes obtiene facilidades para encontrar alojamiento, empleo, y ésta lo introduce en el modo como opera la sociedad receptora (Kearney, 1989; Wellman, 1999). Además, la red tiene un efecto protector en una situación de cambio tan drástico como el que supone la emigración. En ella la gente se siente cómoda, segura, casi como entre los suyos en el lugar de origen (Marina, 2000: 62). De manera que la red es un recurso invaluable cuando se trata de adaptarse a las nuevas circunstancias que se derivan de la migración.

Así pues, la migración es un fenómeno que genera diferencias y experiencias nuevas, lo que abre posibilidades a las localidades, familias e individuos involucrados y, al mismo tiempo, genera tensiones, que se convierten en restricciones (Morin, 2005). Es en torno a estas diferen- 
cias, tensiones y restricciones que se han generado al interior de algunas familias con emigrantes que hablaré en este trabajo.

\section{EL CONTEXTO DE LA INVESTIGACIÓN}

El material que presento en este trabajo fue recopilado en El Salto, una localidad del municipio de Moroleón, que se encuentra al sur del estado de Guanajuato ${ }^{2}$. Por este motivo, la información que se presenta se basa en las interpretaciones que me brindaron personas que permanecen en México. Ellas hablaron acerca de su propia experiencia con la emigración y de la relación que mantienen con sus parientes que se encuentran en Estados Unidos

Guanajuato, junto con Michoacán, Jalisco y Zacatecas, forma parte de lo que algunos autores (Durand y Massey, 2003) han denominado la "región histórica" de la migración, pues de ahí partieron los primeros braceros que laboraron en Estados Unidos desde las primeras dé-

Según el censo efectuado por el centro de salud en el año 2000, en El Salto habitaban 974 personas que vivían en 229 viviendas. El promedio de habitantes por vivienda era de 4.2. La migración internacional estaba muy generalizada en la localidad. La tasa de crecimiento de la población de - $0.36 \%$ entre 1996 y 2000 es un dato elocuente acerca de la extensión del fenómeno (INEGI, 2002: 5). Según datos del Censo del centro de salud, 136 hogares de El Salto, que representaban $60 \%$ del total, tenían por lo menos a uno de sus integrantes viviendo y trabajando

\footnotetext{
2 El trabajo en el campo tuvo lugar de enero a mayo de 2003. Durante esta estancia entrevisté a autoridades civiles y religiosas en el municipio. En la localidad sostuve reuniones con el agente municipal, el dueño de los vehículos que efectuaban el transporte público entre el rancho y las ciudades vecinas, las autoridades escolares de la primaria y la telesecundaria. Realicé entrevistas abiertas y semidirigidas, individuales y colectivas con los integrantes de doce familias. Levanté un cuestionario entre los alumnos de tercero a sexto grado de la primaria $\mathrm{y}$ a todos los de la telesecundaria, que fue respondido por 41 estudiantes de esta última y 47 de la primera. A lo largo del texto me referiré a él como Cuestionario escolar. También revisé el censo que el centro de salud realizó en el año 2000.
}

\section{Cuadro 1. Actividades que realizaban los padres de los estudiantes de primaria y secundaria. El Salto, Guanajuato, febrero de 2003}

\begin{tabular}{l|c|c}
\hline Actividad & $\begin{array}{c}\text { Número } \\
\text { de casos }\end{array}$ & Porcentaje \\
\hline Agropecuaria & 19 & 21.5 \\
\hline Construcción & 5 & 5.5 \\
\hline Construcción/Agropecuaria & 9 & 10 \\
\hline Municipio & 17 & 19 \\
\hline Servicios & 8 & 9 \\
\hline Comercio & 1 & 1 \\
\hline Migración & 29 & 33 \\
\hline Total & 88 & 100 \\
\hline
\end{tabular}

Fuente: Cuestionario escolar.

en Estados Unidos. En total los hogares reportaron 188 personas que radicaban en el país vecino. En este recuento no se consideraba a las familias completas que han emigrado en los últimos años. A través de las genealogías que realicé de dos de las familias entrevistadas detecté, de un total de 61 familias, 18 (29.5\%) casos de familias nucleares completas que en ese momento vivían en Estados Unidos ${ }^{3}$. En 2003, todos los alumnos entre tercero de primaria y tercero de secundaria declararon tener algún pariente en Estados Unidos. De ellos, 29 (33\%) señalaron que sus padres se encontraban trabajando allá; en dos casos (5\%), la que había emigrado era la madre, y 13 (14\%) de estudiantes tenían por lo menos un hermano en el norte ${ }^{4}$. La importancia comparativa de la migración como ocupación entre los padres de familia se aprecia en el cuadro 1.

Debido a la antigüedad que tenía la experiencia migratoria en la localidad, $79 \%$ de los emigrantes se encontraba en Chicago, uno de los primeros destinos de los emigrantes a principios del siglo XX. Le seguían en importancia

\footnotetext{
${ }^{3}$ Las genealogías recuperaron información acerca de cinco generaciones.

${ }^{4}$ Se encontró un comportamiento semejante en las familias de los alumnos de la escuela primaria de La Soledad, municipio de Moroleón, y en la secundaria de El Charco, municipio de Uriangato.
} 
Florida (6\%) y California (3.5\%). Otros destinos eran Carolina del Norte y del Sur, Colorado, Texas, Indiana y Georgia (Censo centro de salud). Las ocupaciones que desarrollaban los migrantes estaban estrechamente relacionadas con el lugar de emigración. Así, encontramos en Chicago, Georgia y Carolina a los que trabajaban en la industria y los servicios (restaurantes, jardinería, fábricas), mientras que en California, Texas y Florida se empleaban mayoritariamente en las actividades agrícolas (corte de naranja y uva).

En la localidad la intención de la migración era obtener mejores ingresos; en el caso de El Salto los ingresos que provenían de la migración se traducían en dos ventajas: por un lado, los familiares de los emigrantes que permanecían en el rancho mejoraban significativamente sus condiciones de vida, pues enriquecían su consumo y la vivienda, y podían brindar mayor escolaridad a sus hijos. Por otro, aunque en menor medida, las remesas eran una posibilidad para invertir en tierras, ganado, pequeños comercios ${ }^{5}$. Cualquiera de estos aspectos en los que se invertía el dinero, siempre se traducía en una movilidad social ascendente. Uno de los resultados de esta mejoría económica era que la migración se convertía en una actividad muy valorada, con gran prestigio en la localidad, independientemente de que en Estados Unidos se laborara en los servicios, la agricultura, la industria o el comercio.

\section{LA TRANSFORMACIÓN DE LAS RELACIONES FAMILIARES}

La migración transformaba las relaciones entre los integrantes de la familia de maneras diversas y contradictorias de acuerdo con la relación de parentesco que se establecía entre ellos. Iniciaré el análisis con los cambios en la forma como los progenitores ven a los hijos que emigran respecto a los que permanecen en el hogar.

\footnotetext{
${ }^{5}$ Canales (2004: 334) documenta un comportamiento semejante en Teocaltiche, Jalisco, también en la región histórica, donde las remesas se usan principalmente para los gastos del consumo doméstico y cada vez menos en inversiones productivas.
}

\section{Hijos que se quedan, hijos que se van}

Cuando un hijo se marchaba a trabajar a Estados Unidos se establecía una diferencia entre el que se fue y el o los que se quedaban. Algunos de los que se quedaban realizaban actividades relacionadas con la producción agrícola y pecuaria, bien en las tierras de la familia o como jornaleros. Otros laboraban en las ciudades vecinas. Sin embargo, estos trabajos (cuidar vacas, abonar la parcela, ser empleado municipal o en algún comercio) eran actividades que estaban a la vista de todos y, por lo mismo, dejaban de ser miradas. Todos sabían qué implicaban y qué era lo que se obtenía de su realización. Además, era lo que se esperaba que esos hijos hicieran. Lo mismo sucedía con el dinero que aportaban. Los dos o trescientos pesos con que contribuían era considerado como parte del presupuesto familiar, como una obligación, ya que vivían bajo el mismo techo y consumían los alimentos que ahí se preparaban. Así, la actividad era desprovista de cualquier carácter extraordinario y se devaluaba, de la misma manera que a la persona que la realizaba.

En el caso de los hijos emigrantes, por el contrario, la familia no conocía directamente ni el lugar ni las características de la actividad que efectuaban, y tampoco las condiciones en que realizaban el trabajo en Estados Unidos. Sólo conocían las historias que narraban los emigrantes acerca de las labores que realizaban en el norte, de las condiciones en que vivían. Además, a la remesa enviada por el hermano desde Estados Unidos se le asignaba otro valor simbólico, tanto porque el hijo ya no vivía con la familia como porque el dinero provenía del trabajo realizado en dicho país.

Otro factor que contribuía a dar mayor valor al trabajo en Estados Unidos estaba relacionado con el hecho de que el hijo que estaba en el norte se convertía en una fuente de seguridad, pues a él se podía recurrir para los gastos imprevistos o extraordinarios como enfermedades, accidentes y celebraciones. El resultado era que la lejanía y el dinero fomentaban la idealización del hijo ausente, mientras que el hijo que permanecía en el rancho no tenía posibilidades de brindar esos apoyos a la familia. Cuando contribuía, su conducta se consideraba el resultado esperado que se derivaba de la convivencia cotidiana. 
La migración también se asociaba con cierta virilidad. Al que se quedaba se le veía como una persona conformista. Se decía que esos jóvenes no desafiaban los riesgos que significa cruzar la frontera - situación que indudablemente se ha vuelto cada vez más peligrosa- y que no era capaz de arriesgarse para mejorar sus condiciones de vida, que no enfrentaba ni superaba los retos que suponía adaptarse a una sociedad de la que todos habían oído hablar mucho, pero que la mayoría no conocía directamente, cuyo idioma no hablaban y en la que sabían que invariablemente las condiciones de trabajo eran duras, pero que ofrecían la oportunidad de mejorar.

\section{Hijos emigrantes y progenitores}

Sin embargo, no todo era positivo. También se presentaban dificultades en la relación entre padres e hijos emigrantes. Los jóvenes solían marcharse poco después de terminar la secundaria, entre los 17 y los 20 años. Algunos emigraban con el padre; otros, cuando el padre no era emigrante, lo hacían en compañía de amigos. Al hacerlo lograban independencia económica, y con ella, cierta autonomía de la familia de origen, lo que les permitía tener acceso a algunas de las prerrogativas de los adultos cuando aún se encontraban en la adolescencia. Así, aunque padre e hijos compartieran la vivienda en Estados Unidos, el primero, en buena medida, perdía su autoridad, pues si los hijos obtenían un empleo por medio de un amigo o conocido - y no del progenitor-, tenían la posibilidad de no informar a éste acerca de sus ingresos, horarios y del uso que hacían del dinero. Cuando hijos y progenitor trabajaban en el mismo lugar, las cosas no eran necesariamente diferentes. Ahí ambos eran contratados por el mismo patrón, ganaban en dólares — con frecuencia cantidades semejantes- y enviaban dinero a México. Incluso, cuando el hijo estaba bajo las órdenes directas del padre en el empleo, solía evitar el control que éste intentaba mantener respecto a sus actividades extralaborales y al uso que hacía del dinero que conservaba para sus gastos.

La madre, por su parte, ignoraba gran parte de las circunstancias en que transcurría la vida cotidiana de su hi- jo. Además, la distancia le impedía saber sus condiciones de vida, actividades laborales y extralaborales, mucho menos ejercer algún tipo de control sobre él. Es decir, el trabajo que realizaban como emigrantes daba a estos jóvenes un estatus y unas condiciones que los colocaban más allá de la autoridad familiar, fuera del alcance de la supervisión del padre o de la madre. Esta situación no se daba de la misma manera con sus hermanos que permanecían en el rancho, quienes continuaban sujetos durante más tiempo a la autoridad materna o bien cumpliendo funciones de hijo parental si el padre estaba ausente, con la responsabilidad que eso implicaba.

Sin embargo, cuando los hijos regresaban a pasar vacaciones al rancho se generaban situaciones contradictorias entre las conductas de los jóvenes, como resultado, por un lado, de la independencia que disfrutaban y de los cambios sufridos debido a su experiencia migratoria, a su exposición a otras culturas, a otra sociedad; y por otro, a la idealización de que eran objeto por parte de los que permanecían en El Salto. Estas contradicciones provocaban tensiones y generaban procesos de cambio a nivel de la localidad y la familia.

Antes de seguir es necesario aclarar que quienes volvían eran los que habían emigrado legalmente, gracias a que su padre tenía la residencia. En la medida en que contaban con el permiso de trabajo podían regresar periódicamente al rancho ${ }^{6}$. Los jóvenes que carecían de papeles preferían permanecer en Estados Unidos para evitar los riesgos y el costo de cruzar la frontera de manera ilegal7 7 . Además, otras investigaciones (Escobar Latapí et al., 1999: 107) han documentado que los jóvenes, al carecer de la responsabilidad de una unidad doméstica, tienden a regresar menos. Entre las familias entrevistadas había dos casos de hijos que se habían marchado a los 17 años y que tenían más de diez años sin volver al rancho, aunque enviaban dinero de manera regular y telefoneaban periódicamente.

${ }^{6}$ En 1986, 60\% de los inmigrantes legalizados por el Acta de Reforma y Control de la Inmigración (IRCA) provenían de la región tradicional de emigración (Escobar Latapí et al., 1999: 103).

${ }^{7} \mathrm{El}$ costo de pasar la frontera era de 1700 dólares en 2003. Actualmente, con la construcción del muro entre México y Estados Unidos y la militarización de la frontera, los costos han alcanzado los 2500 dólares y los riesgos se han multiplicado. 


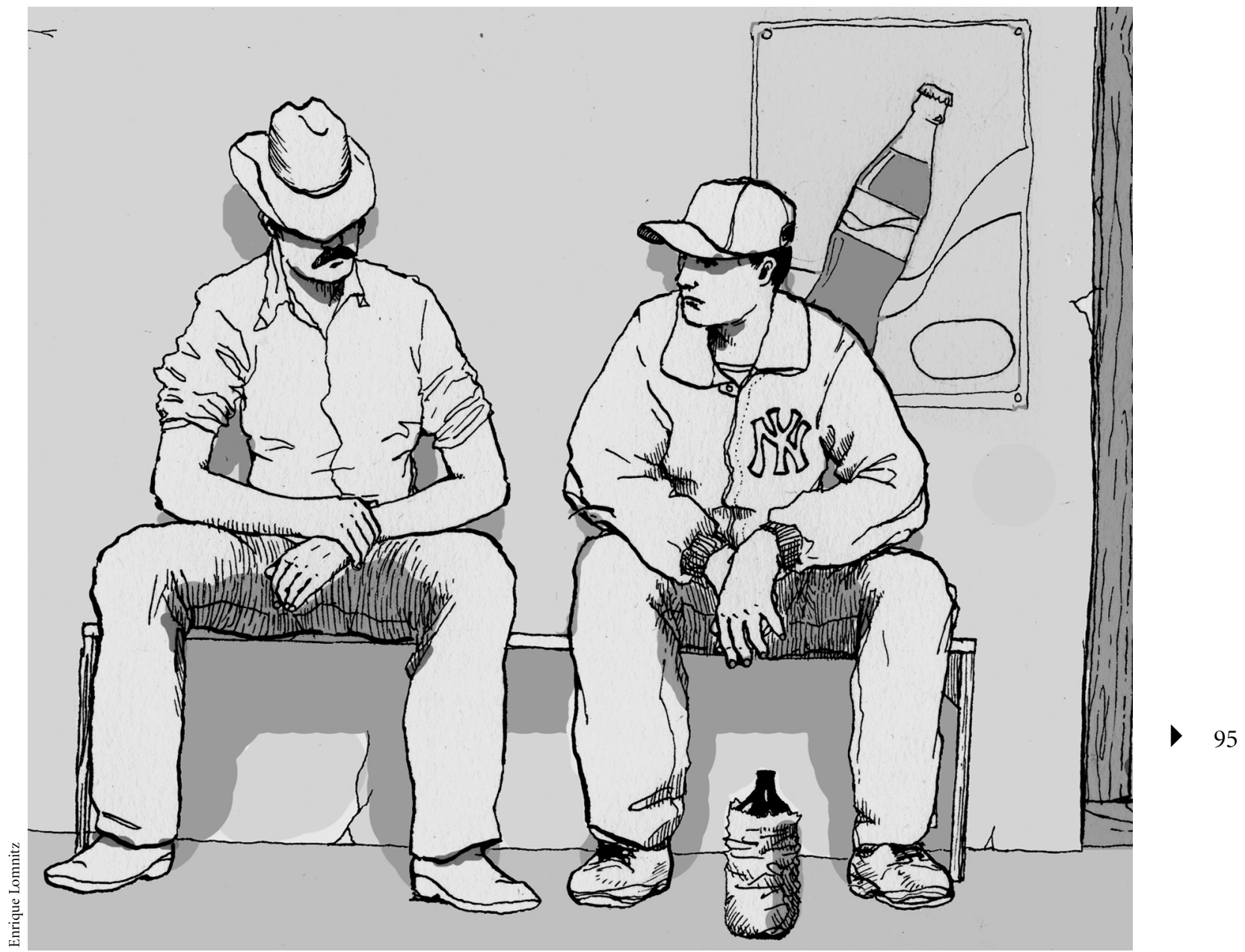

Una vez que los jóvenes regresaban al rancho su interacción con los que se habían quedado iniciaba procesos que desembocaban en la transformación de algunas costumbres de los jóvenes de la localidad. En El Salto los jóvenes que no habían emigrado a Estados Unidos usaban la ropa que sus padres les traían de ese país o que compraban en el tianguis de Moroleón. Sus tardes transcurrían entre las obligaciones domésticas —alimentar y dar agua a los animales, traer leña, entre otras- y hacer sus deberes escolares si todavía asistían a la escuela. Sus actividades sociales consistían en reunirse con sus amigos a jugar en la cancha de basquetbol de la telesecundaria, $y$ los que ya tenían 18 años, en ir al billar de la localidad. Los que trabajaban en Moroleón regresaban por la noche a sus casas, por lo cual pasaban poco tiempo en el rancho. Algunos de estos jóvenes que tenían dinero ingerían bebidas alcohólicas en compañía de los amigos los fines de semana.

Sin embargo, en navidad, cuando regresaban los emigrantes de vacaciones, estas rutinas se transformaban. $\mathrm{Su}$ mera presencia era un factor de cambio, además de que los recién llegados ya no eran los mismos que cuando se habían marchado. Esta transformación se apreciaba en aspectos como la adopción de nuevas palabras y formas de expresarse distintas a las usuales en el rancho. Otro cambio muy notorio, que hacía fácil identificar a los que 


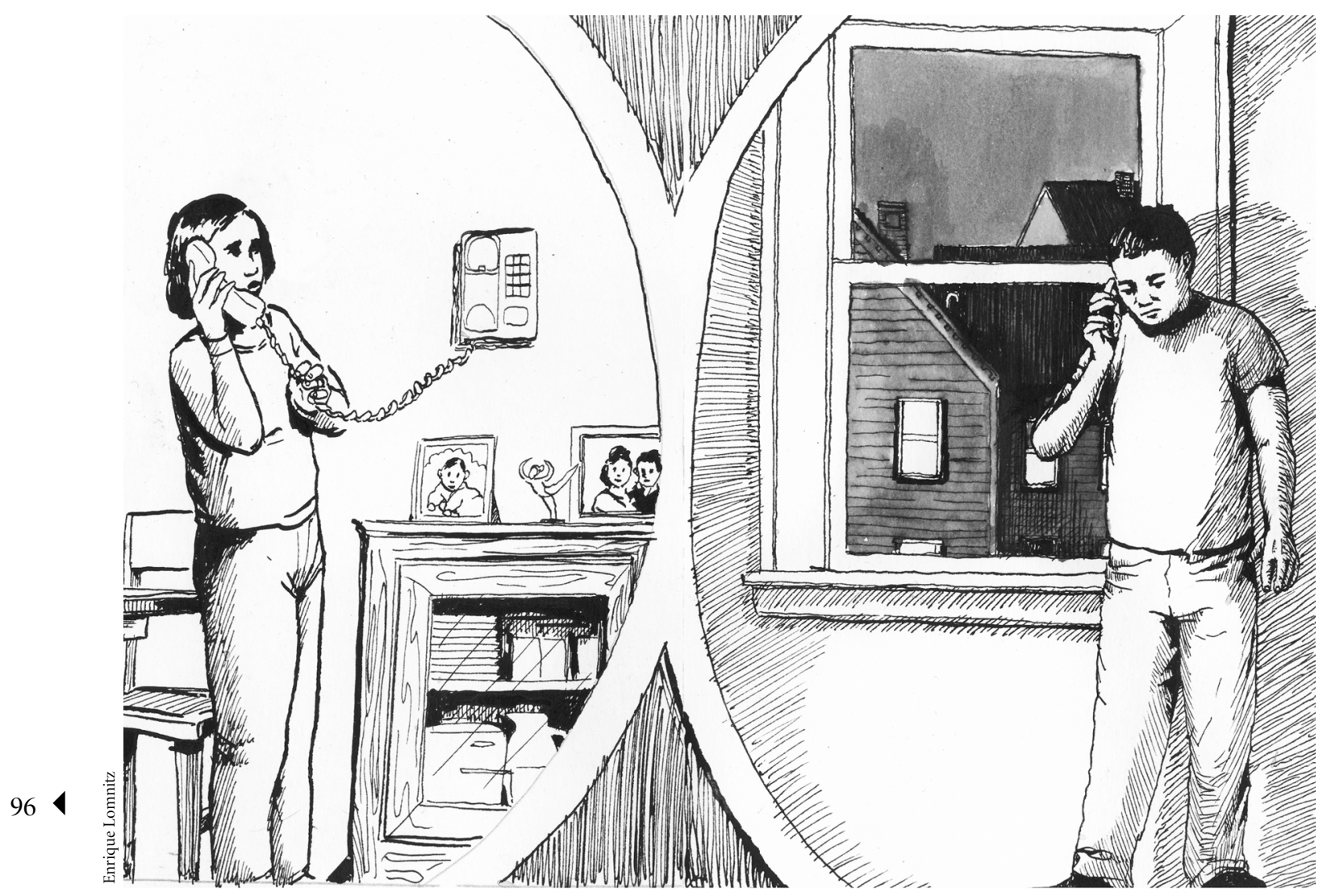

acababan de regresar, era su atuendo, no sólo diferente al que usaban los que habían permanecido en el rancho, sino que con frecuencia era extravagante para las costumbres de la localidad. También disponían de cantidades de dinero que no manejaban sus antiguos compañeros de escuela y exhibían nuevas costumbres, con frecuencia con la intención de hacer notar sus diferencias respecto de la gente que sólo había trabajado en el municipio.

Algunos tenían una actitud desafiante. Tal vez la manifestación más clara de esta actitud era la falta de respeto a la reglamentación que existía para el uso de las instalaciones de la telesecundaria, en particular la cancha de basquetbol $^{8}$. Los profesores se quejaban de que maltra-

${ }^{8}$ Aunque las actividades de la telesecundaria se suspendían a las dos de la tarde, los profesores habían dado autorización para que los alumnos taban las áreas verdes y ensuciaban el patio y las canchas. Además, no se retiraban a la hora establecida. Esto causaba molestia y desaprobación entre los habitantes del rancho y los profesores de la escuela, quienes los acusaban de drogadicción y de ser una mala influencia para el resto de los jóvenes de la localidad.

No obstante la reprobación de los adultos y las autoridades escolares, muchos de los jóvenes que no habían salido de la localidad trataban de adoptar algunas de las costumbres de los recién llegados. Este esfuerzo por imitarlos se apreciaba en la música que escuchaban en aparatos electrónicos que sus padres les habían traído de regalo a su regreso de Estados Unidos, en la adopción

utilizaran las canchas de basquetbol por las tardes, siempre y cuando mantuvieran las instalaciones en buen estado y se retiraran a las siete de la noche. 
de algunas de las modas y en la admiración que suscitaban las historias que narraban los emigrantes. El deseo de imitación estaba relacionado con la idealización de la que eran objeto estos jóvenes cuando se encontraban en Estados Unidos, que interactuaba con el deseo de independencia económica y de autonomía propios de la adolescencia y primera juventud, y que se agudizaban entre estos jóvenes que tenían trabajos mal pagados y, por lo tanto, pocas expectativas de movilidad económica y social. Tampoco gozaban del reconocimiento de su familia ni de los habitantes de la localidad. Así pues, en ocasiones, el joven que había venido de vacaciones regresaba a Estados Unidos acompañado por algún amigo que buscaba dinero, nuevas experiencias e independencia.

Estas circunstancias generaban actitudes contradictorias hacia los jóvenes que emigraban. Los adultos, por un lado, los respetaban porque efectuaban el trabajo que más se valoraba en el rancho, es decir, laborar en Estados Unidos. Por otro, los reprobaban y miraban con desconfianza por las nuevas actitudes que cuestionan el orden y los valores prevalecientes en la localidad. De manera que, cuando estaban lejos y enviaban dinero, estos jóvenes eran fuente de orgullo y seguridad para la familia. Cuando estaban en el pueblo despertaban sentimientos de afecto entre padres y hermanos, y también de reprobación entre esos mismos parientes, así como entre los vecinos de la localidad.

Los jóvenes, por su parte, los admiraban y deseaban lo que tenían: independencia y dinero, lo que motivaba que algunos los imitaran, no sólo en las conductas que mostraban en el rancho, sino que también se marcharan a Estados Unidos a trabajar. No obstante esta admiración e imitación, había otros que reprobaban sus conductas.

\section{Padres emigrantes e hijos}

Acabo de mencionar algunas de las características de la relación de los padres con los hijos emigrados. Ahora me ocuparé de la relación de los padres emigrantes con su progenie que permanecía en el rancho. Esta relación era diferente, por un lado, de la que mantenían los padres que no emigraban y, por otro, de la que establecía la esposa que se quedaba en la localidad con los hijos. Una de estas diferencias era que los padres emigrantes no convivían cotidianamente, sin embargo, esto no significaba que entre ellos no hubiera interacciones, sino que éstas se plasmaban en una forma de relación diferente que contribuía a la organización del sistema familiar.

Estas interacciones eran de distinta índole. Una de ellas se concretaba en el envío regular de las remesas. Sin embargo, el dinero no era la única relación que establecían con su cónyuge y progenie. También mantenían comunicación permanente con la esposa y prole que estaba en el rancho. Esto ha sido posible, en los últimos años, gracias a las telecomunicaciones. La proliferación de líneas telefónicas y el abaratamiento de los costos de las llamadas de larga distancia internacional han permitido a los padres ausentes telefonear a México de manera periódica para enterarse de los avances o tropiezos escolares y de la conducta de sus hijos e hijas. Así, los felicitaban, animaban o reprendían; les hacían recomendaciones si habían peleado entre hermanos, y los exhortaban a obedecer a su madre y abuelos. Estas interacciones les permitían saber qué sucedía con los suyos y de esa manera conservar su cercanía afectiva y su poder de decisión en los asuntos familiares. Un ejemplo que ilustra esta situación es que varias niñas que concluyeron la primaria no fueron inscritas en la telesecundaria hasta que la madre habló con el padre y éste dio su autorización.

Otro aspecto que desempeñaba un papel importante eran las características de la convivencia con los hijos e hijas durante los periodos de vacaciones en que estaban en el rancho. Así pues, una de las maneras como los padres se incorporaban a la dinámica cotidiana de sus hijos era mediante la participación en actividades que promovía la escuela. Una de ellas era contribuir con trabajo y dinero en las obras de reparación del establecimiento escolar. Los profesores de la primaria y la telesecundaria aprovechaban las primeras semanas de enero para solicitar la participación de los padres de familia en tareas de mantenimiento de la escuela, como construcción de bardas, reparación de mesabancos, pintado de aulas, etc., pues sabían que contaban con el trabajo y el dinero de los progenitores que estaban en el rancho pasando sus vacaciones antes de volver a Estados Unidos. Estos pa- 


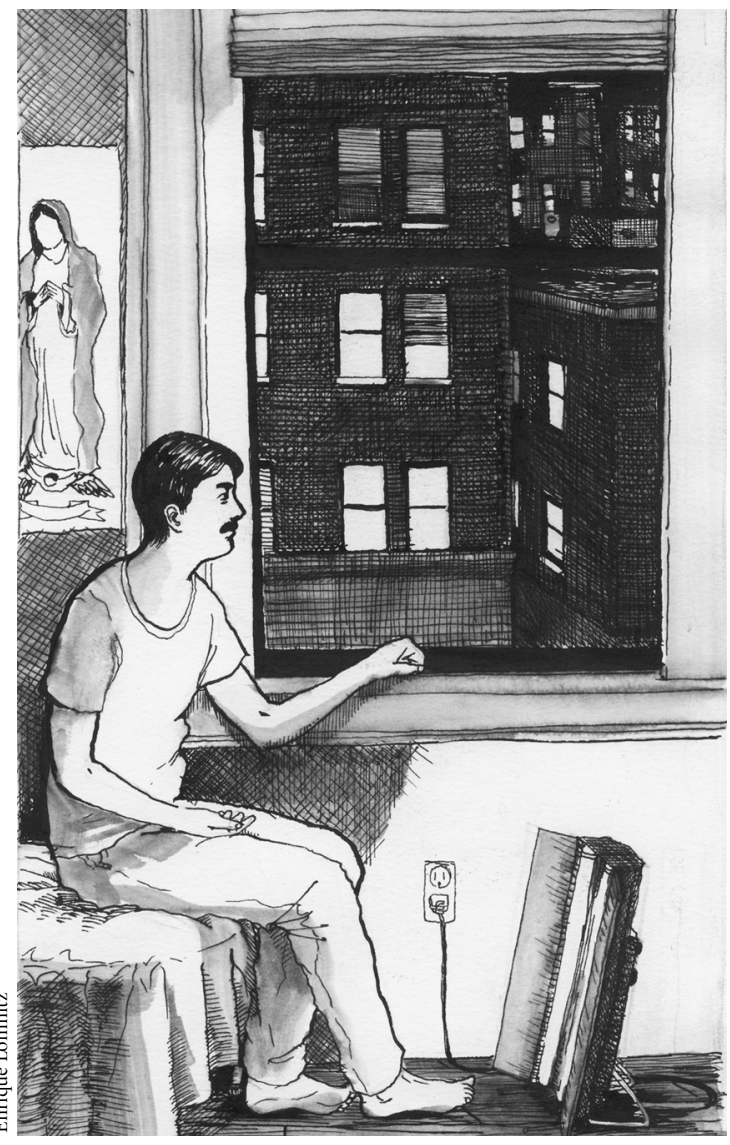

dres respondían a la demanda de la escuela y participaban en dichas labores.

La capacidad del padre para comunicar a su prole un interés real por los pormenores de sus actividades cotidianas - bien fueran domésticas, recreativas o escolares-, para compartir su preocupación por sus problemas, eran centrales en la conformación de la relación del padre con sus hijos en ese proceso de reconocimiento y construcción de la autoridad y el estatus de una persona con la que no convivían cotidianamente.

Otro aspecto de la relación con los hijos era que la experiencia de la emigración permitía al padre contrastar el estilo de vida y los valores estadounidenses con los propios. Así, trataban de reforzar aquellas costumbres y valores que, desde su punto de vista, faltaban en Estados Unidos, y también trataban de transmitir a sus hijos y cónyuge las ventajas que ellos veían del modo de vida de dicho país. Así pues, reforzaban en sus hijos las conductas de respeto y obediencia a los mayores —en particular entre los hijos púberes y adolescentes-y promovían la vigilancia de las hijas. Al mismo tiempo, aceptaban más fácilmente que otros padres que éstas se marcharan a trabajar a las ciudades vecinas o que continuaran estudiando la preparatoria e, incluso, una carrera profesional en la universidad. También procuraban poner en contacto a sus hijos con algunas de las formas de consumo y diversión que estaban a su alcance en Estados Unidos. Para ello traían de regalo videojuegos, aparatos electrónicos, videorreproductoras, y promovían el uso del Internet entre sus hijos.

\section{Los cónyuges}

En la relación entre los cónyuges también se apreciaban diferencias. La primera consistía en que eran parejas que cohabitaban unas cuantas semanas al año. Esto marcaba una forma de relación en la que aspectos de la vida marital, como la sexualidad y los conflictos, no formaban parte de la experiencia cotidiana de la pareja. Esta situación evitaba problemas que enfrentaban los cónyuges que convivían diariamente - peleas y discusiones — , pero provocaba otros, como el hecho de que el cónyuge fácilmente podía convertirse en un extraño. Me extenderé en esto más adelante.

Antes señalé que el estatus del padre ante los hijos descansaba en su responsabilidad económica y en su capacidad de mostrarse cercano a sus intereses sociales y necesidades afectivas. Esto sucedía también con la esposa. Si el padre no criticaba su manera de administrar el dinero, de educar a los hijos, de realizar los quehaceres domésticos y, más aún, si aprobaba explícitamente su desempeño en estas áreas, generaba un sentimiento de confianza en la mujer. Este apoyo propiciaba una situación en la que ella se sentía reconocida en la manera como ejercía sus funciones de madre y ama de casa cuando el varón estaba ausente. Además, con esta aprobación su marido contribuía a legitimar la autoridad de la cónyuge para disciplinar a sus hijos y tomar decisiones en su ausencia. 
Cuando la esposa se sentía apoyada en el aspecto económico y en su autoridad, alimentaba a su vez, de manera cotidiana, la autoridad y el respeto hacia el padre. Así, el estatus de éste era reconocido no sólo por su descendencia y sus parientes, sino también por los parientes de su esposa. En la medida en que el varón brindaba apoyo a su cónyuge en su desempeño materno y doméstico durante las visitas, se establecía un circuito de retroalimentación positiva cuyo resultado era que la relación conyugal funcionaba cordialmente. Entonces, en el origen de esta consolidación del estatus de cada cónyuge, que generaba una relación y una convivencia sin conflictos, estaba la mutua confirmación.

Sin embargo, la armonía no era la única experiencia de estas familias cuando los esposos regresaban durante las vacaciones, ni tampoco era la situación que prevalecía en todas las familias entrevistadas. También había tensiones. Había casos en que la relación conyugal no era armónica y no se daba la mutua confirmación de la que hablé antes. Esto generaba tensiones en la familia: los niños recibían órdenes contradictorias, los cónyuges discutían constantemente. En estas circunstancias la llegada del padre no era motivo de placer. Otro aspecto que alteraba el orden familiar preexistente era cuando el varón solía alcoholizarse, lo que provocaba conflictos entre los cónyuges y, en ocasiones, también con los hijos. Entonces la esposa y la prole añoraban la tranquilidad de la convivencia doméstica cuando el padre estaba en Estados Unidos.

En todos los casos, la llegada de los varones que trabajaban en Estados Unidos alteraba las rutinas familiares y generaba situaciones contradictorias. El padre y los hijos que estaban fuera tenían el deseo de estar con el cónyuge y la prole en el caso de los primeros, y con los padres y los hermanos, si se trataba de los segundos. Para los que estaban en el rancho, la cercanía de la fecha de llegada de los emigrantes generaba una gran expectativa y un gran deseo de ver y convivir con el padre y los hermanos. Sin embargo, una vez que estaban en el hogar, los recién llegados demandaban atención, generaban nuevas tareas domésticas e, incluso, su mera presencia cambiaba las actividades cotidianas, así como las formas y tiempos de realización de los quehaceres de los integrantes que esta- ban permanentemente en el rancho. Se generaba entonces, en ocasiones, una sensación de intromisión para todos los integrantes de la familia. Los que vivían cotidianamente en la casa sentían que había desconocidos en ella, mientras que los recién llegados se sentían como extraños en el hogar al que pertenecían.

\section{REFLEXIÓN FINAL}

Una mirada al fenómeno de las interacciones de los integrantes de familias con emigrantes desde la teoría de la complejidad ha permitido reconocer que la migración es un fenómeno que separa a los integrantes de la familia y que, al hacerlo, paradójicamente contribuye a que permanezcan unidos, pues por un lado, las remesas - que son lo que se busca con la separación de algunos integrantes - permiten la subsistencia material del grupo y, por el otro, los emigrantes, al asumir el compromiso de enviar dinero, validan y consolidan el vínculo que existe entre ellos y los que permanecen en el lugar de origen.

También quisiera señalar que la posición que ocupa el emigrante en la familia interviene en las características de las relaciones que establecen los integrantes entre sí. Estos rasgos, a su vez, generan formas de organización diferentes.

$\mathrm{Si}$ atendemos a las diferencias que genera la migración, veremos cómo en El Salto se traduce en diferencias entre los que se quedan y los que se van; éstas, a su vez, generan procesos contradictorios entre los integrantes de las familias. Estas contradicciones se manifiestan en el nivel de las interacciones y en la carga simbólica que se da a las actividades. Así, por un lado, la migración es una actividad que confiere prestigio a quienes la efectúan. Padres, madres y parientes animan a los jóvenes a emigrar, y el estatus de quienes lo hacen aumenta —más aún, si envían dinero- - Aquellos que no lo hacen se ven relegados a posiciones de poco prestigio al interior de la familia. Así pues, el grupo familiar confiere o resta poder, ánimo, eficacia a sus integrantes (Marina, 2000: 63). Por otro lado, los habitantes de la localidad tienen dificultades para aceptar los cambios que la experiencia migratoria produce en algunos individuos y el resultado es el re- 
chazo hacia ellos. De esta manera, en la localidad se vive una tensión entre otorgar un gran estatus a los individuos que efectúan el trabajo que goza de mayor reconocimiento $y$, al mismo tiempo, reprobar a esos individuos por las conductas y costumbres que adoptaron mientras realizaban los trabajos que les confieren prestigio.

Otro aspecto que también genera diferencias está relacionado con la manera en que se otorga la autoridad. Señalé que la autoridad de quienes están ausentes cotidianamente y frente a los que se marcharon se sustenta en la interrelación de factores económicos (envío de remesas), sociales (confirmar la autoridad del cónyuge, participar en las actividades de la localidad) y afectivos (mostrar interés por la vida de los suyos). En esta interrelación no es raro que la migración, en ocasiones, altere la jerarquía que se suele adjudicar a los padres, lo que dificulta el ejercicio de la autoridad. Jóvenes solteros pueden adquirir mayor estatus que sus progenitores si el padre no emigró, y lo mismo sucede cuando los hijos se convierten en mejores proveedores económicos. Esto genera tensiones entre padres e hijos migrantes.

100 La migración también provoca tensiones de otro tipo, vinculadas con la reorganización del sistema familiar que se hace necesaria ante la reincorporación de uno o más de sus miembros. De esta manera, quienes se marchan para posibilitar la permanencia de la familia, quienes gozan de mayor prestigio, son también aquellos que, cuando regresan, con sus conductas y costumbres recién adquiridas cuestionan la organización prevaleciente, lo que hace que sean mirados con desconfianza y reprobados.

\section{Bibliografía}

Arias, Patricia y Jorge Durand, 2005, La vida en el norte. Historia e iconografía de la migración México-Estados Unidos, El Colegio de San Luis, Universidad de Guadalajara, México.

Bateson, Gregory, 1991, Pasos hacia una ecología de la mente. Una aproximación revolucionaria a la autocomprensión del hombre, Lohlé, Lumen, Argentina.

Canales, Alejandro I., 2004, "Vivir en el norte: perfil sociodemográfico de los hogares perceptores de remesas en una región de alta emigración", en Ariza y De Oliveira (coords.), Imágenes de la familia en el cambio de siglo, Instituto de Investigaciones Sociales, Universidad Nacional Autónoma de México, México, pp. 321-355.

Devereux, George, 1996, De la ansiedad al método en las ciencias del comportamiento, Siglo XXI, México.

Durand, Jorge y Douglas Massey, 2003, Clandestinos, Miguel Ángel Porrúa, Universidad Autónoma de Zacatecas, México.

Escobar Latapí, Agustín, Frank D. Bean y Sydney Weinraub, 1999, La dinámica de la emigración mexicana, Centro de Investigaciones y Estudios Superiores en Antropología Social, Miguel Ángel Porrúa, México.

INEGI (Instituto Nacional de Estadística, Geografía e Informática), 2002, Guanajuato. Perfil sociodemográfico. XII Censo general de población y vivienda, 2000, INEGI, Aguascalientes.

Kearney, Michael, 1986, "From the Invisible Hand to Visible Feet: Anthropological Studies of Migration and Development", Annual Review of Anthropology, núm. 15, pp. 331-361.

Marina, Jose Antonio, 2000, Crónicas de la ultramodernidad, Anagrama, Barcelona.

Morin, Edgar, 2001, El método. La naturaleza de la naturaleza, Cátedra, Madrid.

— 2005, El paradigma perdido. Ensayo de bioantropología, Kairós, Barcelona.

Prigogini, Ilya, 1997, El fin de las certidumbres, Taurus, Madrid.

Von Bertalanffy, Ludwig, 1995, Teoría general de los sistemas, Fondo de Cultura Económica, México.

Wellman, Barry, 1999, "The Network Community: An Introduction", en Wellman (ed.), Networks in the Global Village. Life in Contemporary Communities, Westview Press, Boulder, Colorado, pp. 1-47. 